\title{
Handling Performance Investigation on Geometrical Frame of Three Wheels Vehicle
}

\author{
Wibowo, Lutfianto, Triyono, Sinki, NurulMuhayat \\ Mechanical Engineering, University of SebelasMaret, Surakarta \\ Jl. Ir. Sutami 36A Surakarta, Indonesia \\ Email:wibowo_uns@yahoo.com
}

\begin{abstract}
The aim of investigation was to analyze geometrical effects of frame on vehicle handling. Analysis had been done on prototype of three wheels vehicle. The prototype was designed using revolute joint frame to gain better vehicle handling. Revolute joint frame on the vehicle prototype could be set up into three configurations, below the road plane of irc (instantaneous rotation center), on the road plane or netral number of irc, and above the road plane of irc. Handling performances of three configurations were analyzed by computer simulation using Universal Mechanism 5.0 software and qualitative experiment on U-turn track test. The simulation was set up at the $15 \mathrm{~m} / \mathrm{s}$ constant velocity, gained the values of the koch index on below road plane, on the road, and above the road of ircare $16.15 \mathrm{Ns}^{2} / \mathrm{rad}, 6.41 \mathrm{Ns}^{2} / \mathrm{rad}$, and $2.82 \mathrm{Ns}^{2} / \mathrm{radrespectively.} \mathrm{The} \mathrm{lowest} \mathrm{koch} \mathrm{index} \mathrm{number} \mathrm{showed} \mathrm{the} \mathrm{best} \mathrm{performance} \mathrm{based} \mathrm{on} \mathrm{U-turn}$ qualitative tests. The results agreed with qualitative experiment, that all of test drivers decided that frame configuration of irc at above the road plane was more suitable on curving track, whereas the irc at the below road plane was more stable on straight track.
\end{abstract}

Keywords : revolute joint frame, steering torque, roll angle, koch index.

\section{Introduction}

Handling is ability to drive easy. Level of handling can be obtained with computer simulations and testing vehicles with a test maneuver driving. Information about the handling was never published by the manufacturer. The manufacturers only provide some of the technical information specifications such as maximum speed, acceleration, torque, the top distance between the axis of the wheel, the weight of the vehicle, and others. The assessment is usually done subjectively by the independent agency of print media or electronic with testing on a race track or highway. Test driver attempted to explore the vehicle to know the vehicle's maneuverability do motion as fast as possible without neglecting safety and comfortibility. Three-wheeled vehicles that are sold less attractive to consumers because the modelsare almost the same at any production. ${ }^{1}$

Many riders complained about the amount of power required to drive a three-wheeled vehicle, especially on turning roads. However a threewheeled vehicle is considered to be a good solution for its compactness, maneuverable, stability, and load capacity. One of the solutions to reduce the burden while on driving is developing of threewheeled vehicle with innovative frame. The vehicle prototype using a revolute joint frame for connecting the front and rear of the chassis-frame, so that the vehicle can move dynamically like a motorcycle.

\section{Measuring Handling Vehicles with U- Turn Test}

Experiment and simulation are useful to study the dynamic behavior of vehicle data. The motorcycle was assumed to be the systems with some input controls (steering, torque angle and speed) and some outputs of the kinematics and dynamics. The behavior of motorcycles described by functions that connect the input and output in a typical maneuver such as slalom, steady turning, lane change, obstacle and avoidance. The requirements of different variety tests on motorcycles are consequence of the fact that it is not possible to divide a path into a simple curve or straight, because the rider must adjust the maneuvering trajectory. For example, control of vehicle on a slalom test course differs from steady turning maneuver for rotational at the same speed. Motorcycle handling characteristics are not only depend on the value of the torque on certain conditions, but also by other variables, such as the 
vehicle speed and the time required to reach a certain angle against vertical (angles of roll speed).

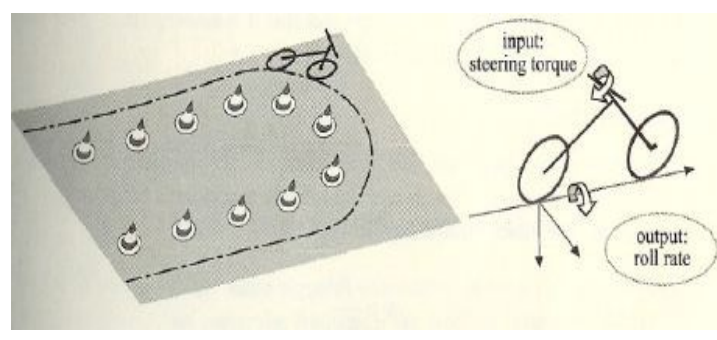

Fig.1.U-turn test path

J. Koch (1978) experimented U-turn test, resulting in the formula for updating the evaluation capacity of the vehicle on the path $\mathrm{U}$ :

Koch index $=\frac{\tau_{\text {peak }}}{V \cdot \emptyset_{\text {peak }}}\left[\frac{N}{\mathrm{rad} / \mathrm{s}^{2}}\right]$

$$
\begin{aligned}
& \tau_{\text {peak }} \quad \begin{array}{l}
=\text { the maximum torque value } \\
\text { Steering }
\end{array} \\
& \varnothing_{\text {peak }} \quad \begin{array}{l}
=\text { the value of the maximum speed } \\
\text { of the roll }
\end{array} \\
& \mathrm{V} \quad=\text { speed forward }
\end{aligned}
$$

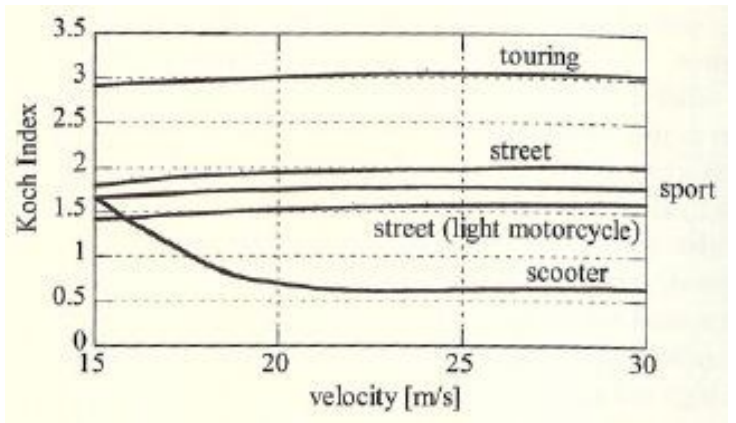

Fig. 2. Koch index graphs for some types of vehicles.

Koch index shows the ability of a motorcycle when turning (turn radius) with the speed of the vehicle is increased depending on the type of motorcycle. The value of maximum torque steering and the speed of the roll obtained on phase transitions, not in a steady condition. A motorcycle with a good handling based on small value of the formula, Koch index is obtained on the speed of the vehicle's speed and high torque while the wheel roll is low. Transition condition when entering the path most affected by high center of mass, inertia of the front wheel, front frame inertia (related to the axis of the wheel), inertial frame (which is related to the axis yaw and roll axis). Figure 2. shows the index
Koch several types of motorcycles when entering the path $\mathrm{U}$ had a radius up to $100 \mathrm{~m}$. The picture shows that while speed continues to increase, the value of the index tends towards a certain boundaries of Koch. Simply, control maneuverability a scooter motorbike is easier than touring types. ${ }^{2}$

\section{Three WheeledVehicle with Revolute Joint Frame}

Three wheeled vehicle frame is divided into two parts consist of front frame and rear frame that join by revolute joint frames. This arrangement allows the front frame can tilt in order on dynamic move in the direction of turn vehicles. This join is an innovative aspect of the vehicle that are expected on the significant effect of dynamical behavior vehicle.

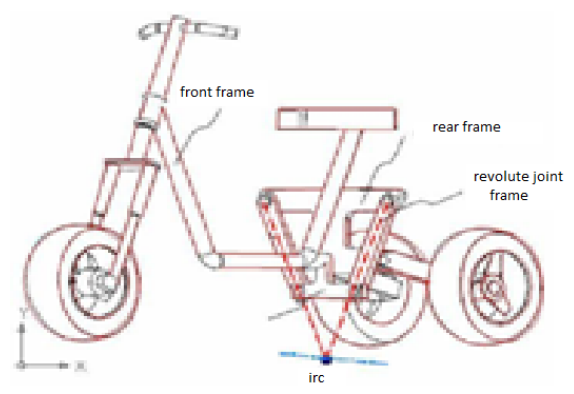

Fig. 3. Dividing frame into two.

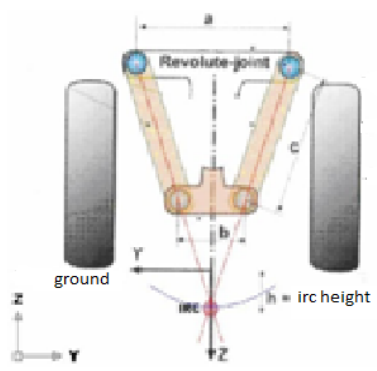

Fig.4. Revolute joint frame configuration.

Revolute joint frame consists of four rods that the geometris can change. Top rod is a part of rear frame that fixed positionperpendicular with the rear wheels.Bottom rod b is a part of front frame that can rotate in instaneous tilting axis.Rear frame and front frame are connected by two rods c that can move according to the force of the front frame (rod a). Join of two axis of the rod c shows the irc. Changing of the distance joint on the shaft $\mathrm{a}, \mathrm{b}$ and 
c cause change distance irc from surface of the road. There are three configurations of revolute joint frames based on irc's position, namely: the position of irc above ground (the parameter $\mathrm{h}$ is positive), ircon ground level $(\mathrm{h}=0)$, and ircon under ground ( $\mathrm{h}=$ negative). They give significant effects of dynamical behavior of the vehicle ${ }^{3}$.

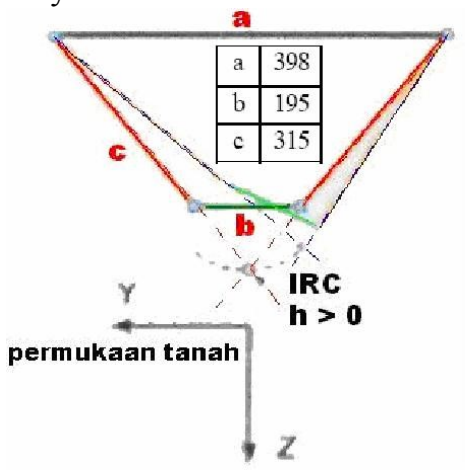

Fig. 5.irc above the ground

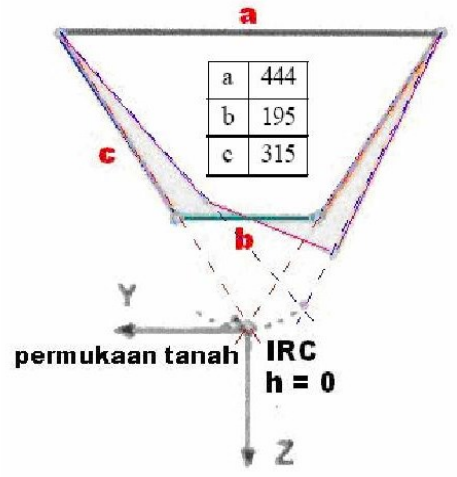

Fig. 6. irc on the ground (neutral)

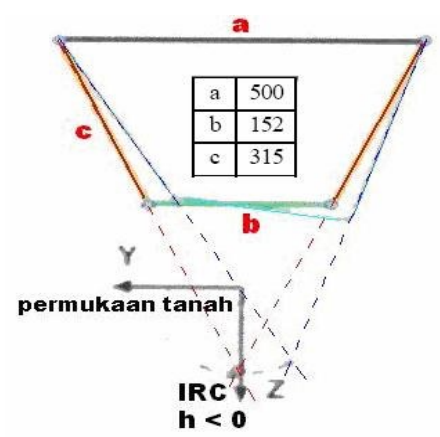

Fig. 7. irc on the underground

\section{Universal Mechanism Simulation Software}

Universal Mechanism software involves many problems of dynamics and mechanism. The mechanical system is described with tools that represent the system of rigid bodies with various elements of style and kinematics, so called multibodi system ${ }^{4}$.

UM work Diagram:

- initials of mechanical system.

- input data for the model.

- models (body, joints and style element.)

- generating of equations of motion

- $\quad M(q) \ddot{q}+k(\dot{q}, q)=Q(\dot{q}, q, t)$

- simulation of the dynamics of the model.

\section{MATLAB}

Control system using MATLAB integrates visualization, mathematical computing, and a powerful language to provide a flexible environment for technical computing. MATLAB has a highly optimized matrix and vector calculations, it is offers an intuitive language for expressing problems and their solutions both mathematically and visually ${ }^{5}$. MATLAB typically uses:

- Numeric computation and algorithm development

- Symbolic computation (with the built-in Symbolic Math functions)

- Modeling, simulation, and prototyping

- Data analysis and signal processing

- Engineering graphics and scientific visualization

\section{Results}

Results of simulation for Vehicle configuration of irc above groundirc $=$ positive. (fig. $8-$ fig. 10 )

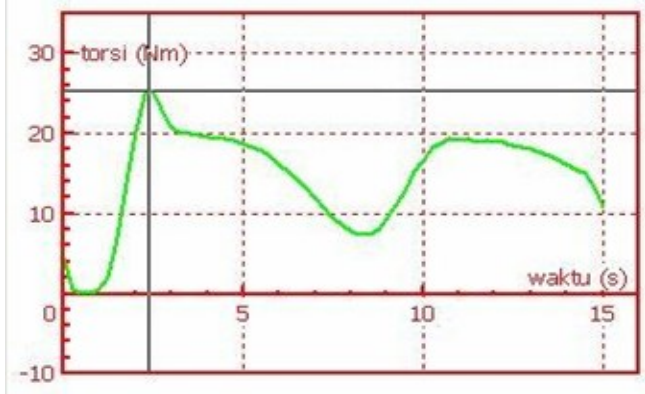

Fig. 8. Peak of steering torque $25,36 \mathrm{~nm}$

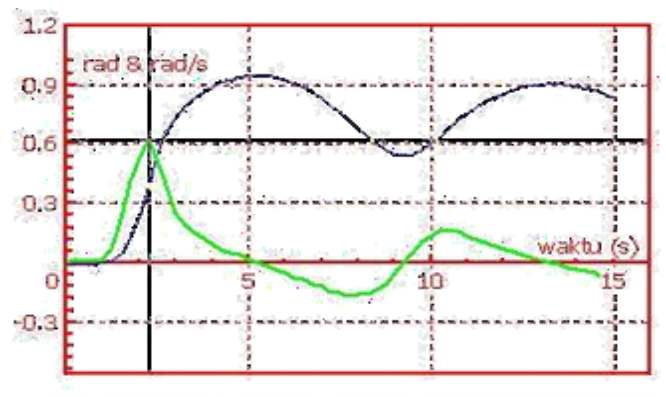

Fig. 9. The angular velocity of roll $0.621 \mathrm{rad} / \mathrm{s}$ 


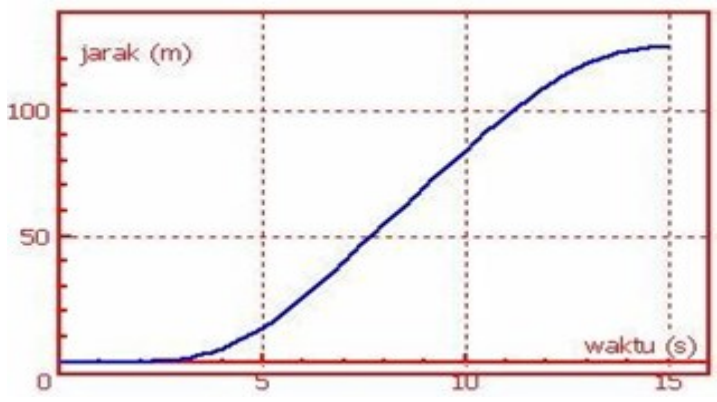

Fig. 10.yaw

Parameters measured from the U-turn simulation test to calculate the performance handling based on Koch index, among others, is steering torque and angular velocity of roll order. From Figure 5 can be known of such influential variable value, namely: $\tau_{\text {peak }}$ (peak rate of torque Steering) $=25,36 \mathrm{Nm}$ $\varphi_{\text {peak }}($ peak rate of roll speed $)=0,62 \mathrm{rad} / \mathrm{s}$

$$
\mathrm{V} \text { (velocity) } \quad=15 \mathrm{~m} / \mathrm{s}
$$$$
\text { Koch indeks }=2,82 \mathrm{Ns}^{2} / \mathrm{rad}
$$

Table 1. result of simulation for position of the irc.

\begin{tabular}{lcccl}
\hline \multicolumn{1}{c}{ irc } & \multicolumn{1}{c}{$\boldsymbol{\tau}_{\text {peak }}$} & $\boldsymbol{\varphi}_{\text {peak }}$ & speed & \multicolumn{1}{c}{ Koch index } \\
\hline positive & $25,36 \mathrm{Nm}$ & $0,62 \mathrm{rad} / \mathrm{s}$ & $15 \mathrm{~m} / \mathrm{s}$ & $2,82 \mathrm{Ns}^{2} / \mathrm{rad}$ \\
neutral & $23,09 \mathrm{Nm}$ & $0,24 \mathrm{rad} / \mathrm{s}$ & $15 \mathrm{~m} / \mathrm{s}$ & $6,41 \mathrm{Ns}^{2} / \mathrm{rad}^{2}$ \\
negative & $36,33 \mathrm{Nm}$ & $0,15 \mathrm{rad} / \mathrm{s}$ & $15 \mathrm{~m} / \mathrm{s}$ & $16,15 \mathrm{Ns}^{2} / \mathrm{rad}$ \\
\hline
\end{tabular}

\section{Qualitative Testing Handling Vehicles}

Qualitative testing is done by some testers on the U-turn trajectory. In this test, the riders must not to spur the vehicle at the top level of the maximal ability of machine, because it is difficult to do so in a short time without a long time trainning. After the examiners tested three-wheeled vehicle in all number irc respectively, they gived qualitative data. The test results are also affected by the level of sensitivity of each testers. Qualitative testing results summary of 30 respondents indicated below,

- The dimensions of the vehicle ride comfort (sitting position, handle and foot step). $26.7 \%=$ good, $73,3 \%=$ fair.
- Requiring roll angle is like a motorcycle when turning. $100 \%=$ yes.

- The comments of test driver on innovative revolute joint frame on three-wheeled vehicles? $100 \%=$ stated it is good.

- Influence of applying revolute joint frames when driving a vehicle. $100 \%=$ yes, make it easier.

- Comparison among all number of the irc. 100\% $=\mathrm{h}$ negative is the easiest on the straight road, $\mathrm{h}$ positive is the easiest on the turning road.

- Where the trajectory of $U$ that need the biggest power steering ? 100\% stated at the beginning.

\section{Conclusion}

The configuration of revolute joint frames has a significant influence to the three-wheeled vehicle handling. The number of Koch index on irc above the ground, on the ground, and under the ground are 2,82 Ns2/rad, 6,47 Ns2/rad, $13.36 \mathrm{Ns} 2 / \mathrm{rad}$ respectively. The configuration of irc above ground has the easiest handling. The results agreed with qualitative experiment, that all of test drivers decided that frame configuration of irc at above the road plane was more suitable on curving track, whereas the irc at the below road plane was more stable on straight track.At the beginning of the curve trajectory requires a greater steering effort.

\section{References}

1. Nyoman, I.S., Teknologi Otomotif, GunaWidya, Surabaya. Indonesia. (2001). Pp 15-30

2. Cossalter, Vittore, Motorcycle Dynamic 2nd Edition, Lulu, Modena : University of Padua. (2006). Pp 319-326

3. Agostinetti, P., Cossalter, V., Ruffo, N. Experimental analysis of handling of a three wheeled vehicle, Modena : University of Padua. (2003)

4. Pogorelov, D., Prof., Universal Mechanism Technical Manual, Rusia : Bryansk State Technical University, (2007)

5. Dukkipati, Rao, Analisys and Design of Control System Using MATLAB, New Age International. New Delhi. (2006). Pp 125-143 